\title{
SERVIÇO DE ATENDIMENTO MÓVEL DE URGÊNCIA E AS URGÊNCIAS PSIQUIÁTRICAS
}

\author{
Diego Bonfada* \\ Jacileide Guimarães ${ }^{\#}$
}

\begin{abstract}
RESUMO. Este estudo propõe-se a discutir os princípios e diretrizes que norteiam a atenção de urgência prestada pelo SAMU diante de uma crise ou urgência/emergência psiquiátrica, tendo como parâmetro as discussões que embasaram a reforma psiquiátrica. Trata-se de um estudo aplicado, de abordagem qualitativa na configuração de uma revisão de literatura que estabeleceu um diálogo entre os autores para atingir o objetivo proposto. As diretrizes que norteiam a assistência prestada pelo SAMU contribuem para uma intervenção em crise pautada no paradigma da clínica tradicional, em que as prioridades são a contenção e o transporte ao hospital psiquiátrico. Destarte, a articulação com a rede de saúde mental, a efetivação do apoio matricial, investimento em capacitação profissional e a operacionalização real do Programa Permanente de Formação de Recursos Humanos para a Reforma Psiquiátrica são medidas que podem contribuir para a consolidação de uma intervenção em crise pelo SAMU mais humanizada e articulada com a reforma psiquiátrica brasileira.
\end{abstract}

Palavras-chave: Serviços de saúde; assistência à saúde; saúde mental.

\section{MOBILE EMERGENCY SERVICE AND PSYCHIATRIC EMERGENCY}

\begin{abstract}
The goal of this study is to discuss the principles and the guidelines that surround the urgency attention provided by SAMU (Mobile Emergency Service) during a crisis or a psichiatric emergency having as parameter the discussions that support Psychiatric Reform. It's an applied study with a qualitative approach at the configuration of a literature review that established a dialogue between the Authors to achieve the proposed goal. The guidelines that surround the urgency attention provided by SAMU contribute to an intervention in a crisis based on traditional clinical paradigm where the priorities are the containment and the transport to the psychiatric hospital. Therefore the negotiation with the Mental Health Network, effective matrix support, investiment in professional training and the real operation of Permanent Program Training of Human Resources to the Psychiatric Reform are things that can help the consolidation of a crisis intervention by a SAMU more humanized and combined with the Brazilian Psychiatric Reform.
\end{abstract}

Key words: Health Services; health assistance; mental health..

\section{SERVICIO DE ATENCIÓN MÓVIL DE URGENCIA Y LAS URGENCIAS PSIQUIÁTRICAS}

\begin{abstract}
RESUMEN. Este estudio propone la discusión de los principios y directrices que orientan la atención de urgencia prestada por el SAMU durante una crisis o urgencia/emergencia psiquiátrica, teniendo como parámetro las discusiones que apoyaran la Reforma Psiquiátrica. Se trata de un estudio aplicado, de enfoque cualitativo en la configuración de una revisión de la literatura siendo establecido un diálogo entre los autores para lograr el objetivo propuesto. Las directrices que guían la atención prestada por el SAMU contribuyen a una intervención en crisis regida por el paradigma de la clínica tradicional, donde las prioridades son la contención y transporte a un hospital psiquiátrico. Por lo tanto, la relación con la red de salud mental, la ejecución de la matriz de soporte, la inversión en capacitación laboral y el funcionamiento real del Programa Permanente de Formación de Recursos Humanos para la Reforma Psiquiátrica son medidas que pueden contribuir a la consolidación de una intervención en crisis por el SAMU más humanizada y concerniente con la Reforma Psiquiátrica brasileña.
\end{abstract}

Palabras-clave: Servicios de salud; la asistencia sanitaria; salud mental.

\footnotetext{
Mestre em Enfermagem e Aluno de doutorado do Programa de Pós-graduação em Saúde Coletiva da Universidade Federal do Rio Grande do Norte. Professor Assistente da Universidade do Estado do Rio Grande do Norte, Brasil.

\# Doutora em Enfermagem Psiquiátrica e Saúde Mental pela Universidade de São Paulo. Professora do Programa de Pósgraduação em Enfermagem da Universidade Federal do Rio Grande do Norte, Brasil.
} 
A Reforma Psiquiátrica caracteriza-se como um movimento social e político que contribuiu para a desconstrução da proposta de internação manicomial como estratégia central para o atendimento do sujeito em sofrimento psíquico. Além disso, ampliou a discussão a respeito da psiquiatria e seu modelo de assistência, bem como sobre o preconceito e o estigma estabelecidos em torno do conceito de periculosidade do paciente psiquiátrico. Tais discussões foram consolidadas nas diretrizes da política, da legislação e dos serviços de atenção à saúde mental no Brasil (Amarante, 1999).

Embora a Reforma Psiquiátrica Brasileira não tenha fechado as portas dos hospitais psiquiátricos, a partir da promulgação da Lei 10.216 de 2001 foram criados critérios mais estritos para o seu funcionamento, com uma drástica redução dos leitos disponíveis e a diminuição das internações. Em contrapartida, foram criados serviços substitutivos que oferecem uma abordagem terapêutica pautada na necessidade da convivência comunitária, trabalhando a (re)inserção social dos pacientes a partir das potencialidades e entraves encontrados nos contextos locais.

Dessa maneira, está sendo estruturada paulatinamente nos serviços públicos brasileiros uma rede de atenção à saúde mental, que conta com a assistência prestada em instituições específicas da área. Esses serviços, entre os quais, se destacam os Centros de Arenção Psicossocial - CAPSs - oferecem uma alternativa terapêutica que procura evitar o internamento dos sujeitos em sofrimento psíquico. Ademais, a assistência em saúde mental não está restrita a esses serviços específicos, pois está estipulado nas políticas de saúde que as unidades básicas vinculadas à Estratégia de Saúde da Família ESF, os hospitais gerais e qualquer outra instituição do Sistema Único de Saúde - SUS devem assumir responsabilidades para com a assistência de saúde mental (Ministério da Saúde, 2007).

Antes isolada e escondida atrás dos muros dos manicômios, hoje as crises ganham o espaço social, com a diminuição dos leitos e das internações. Isso gerou também a necessidade de criar serviços substitutivos para dar conta dessa nova demanda. Nesse contexto, a Política Nacional de Atenção às Urgências ratificou a responsabilidade do Serviço de Atendimento Móvel de Urgência - SAMU no que tange à assistência em crises psíquicas (Portaria 2048/GM, 2002).

$\mathrm{O}$ papel do SAMU no tocante à assistência às urgências psiquiátricas foi ratificado durante a Primeira Oficina Nacional de Atenção às Urgências em Saúde Mental, que aconteceu na cidade de Aracaju- SE no ano de 2004. O evento foi o primeiro diálogo prático para operacionalizar a articulação entre a Política Nacional de Atenção às Urgências e a Política Nacional de Saúde Mental (Ministério da Saúde, 2007).

Essa transferência legal de responsabilidade, em que se atribuem novas e específicas demandas a profissionais e serviços, deve ser acompanhada da preparação e da capacitação do espaço assistencial para que a atenção torne-se realmente resolutiva e integral, pois a atuação com sujeitos em sofrimento psíquico requer competências peculiares dos profissionais e serviços envolvidos.

Destacam-se inicialmente algumas implicações conceituais. A palavra "crise" é originária da palavra grega krisis, que circunscreve uma situação na qual uma decisão precisa ser tomada. Assim, essa palavra assume, desde suas origens, um sentido relacionado a transição, separação, desequilíbrio, transitoriedade e, acima de tudo, a uma oportunidade de crescimento. Nesse sentido, a crise dever ser apreendida como um momento que precisa também ser cuidadosamente trabalhado por profissionais qualificados para que os sujeitos desfrutem do seu potencial transformador e criativo, pois, embora salte aos nossos olhos todo o sofrimento vivenciado pelo indivíduo, podemos percebê-lo em seu momento de metamorfose, de saída de um lugar sócio- historicamente construído para outro que está sendo reconstruído. Destarte, não se nega que a crise é um momento em que o sujeito extravasa toda a sua angústia e sofrimento, a ponto de se desprender de sua realidade social e corporal, e que isso pode, em certas situações, trazer consequências danosas ao indivíduo e para os que o cercam. Não obstante, esse risco nem sempre está presente, e o desprendimento da realidade que o sujeito está vivenciando nesse momento não implica a ausência de sensações e afetos, nem da sua condição humana, por mais estranha que a situação possa demonstrar-se (Ferigato, Campos \& Ballarin, 2007).

Com base nos conceitos de crise, ressalta-se que nem toda crise é uma urgência ou emergência psiquiátrica, por isso não deve ser tratada incondicionalmente como tal, pois as definições de urgência e de emergência médica nem sempre se aplicam sob as mesmas égides no campo da saúde mental (Oliveira, 2002). Não obstante, na Portaria 2048/GM (2002), que regulamenta o atendimento das urgências e emergências, a crise em saúde mental é frequentemente tratada como urgência psiquiátrica, sendo tida como uma das atribuições do SAMU 
conjuntamente com a rede de atenção à saúde mental, a polícia e o corpo de bombeiros.

Nessa perspectiva, Jardim (2008) acrescenta que “(...) a crise que deveria ser cuidada a partir dos princípios de vinculação e acolhimento da existência, do sofrimento do outro, ganha o rótulo de urgência psiquiátrica, processo que traz consigo alterações microfísicas nefastas" (p.17). Assim, a crise deve ser assistida sob a ótica da humanização e da integralidade do atendimento em saúde e, como qualquer fenômeno relativo ao processo saúde/doença, também necessita de profissionais que dominem conhecimentos teóricos próprios de sua área de atuação e sejam capazes de colocar as necessidades dos sujeitos como elementos centrais de suas intervenções.

Não obstante, a Política Nacional de Atenção às Urgências ainda aponta a crise psiquiátrica como objeto de intervenção da polícia, mesmo diante do seu completo despreparo para esse tipo de atuação e de seu caráter histórico de agente de repressão e manutenção da ordem. Isto não significa que a ajuda policial não possa ser solicitada ou que medidas mais drásticas não possam ser tomadas no caso de um paciente em crise que esteja ameaçando de forma concreta sua própria vida ou a de terceiros (emergência psiquiátrica). A crítica é relativa ao despreparo policial e, acima de tudo, ao uso indiscriminado de medidas extremas em situações de crise ou de urgência psiquiátrica, nas quais os sujeitos mostram-se até certo ponto cooperativos ou abertos ao diálogo, à interação e à adoção de medidas terapêuticas que visem à vivência positiva daquele momento tão traumático.

Somando-se a isso, o SAMU, serviço de atenção pré-hospitalar historicamente atrelado ao paradigma da clínica tradicional de urgência e de emergência, na maioria das vezes nega ou não pratica aquilo que a atenção à crise mais necessita, ou seja, empatia, diálogo, corresponsabilização, humanização, subjetividade e criatividade (Jardim, 2008).

Em face do exposto, a discussão, neste artigo, circunscreve-se nessa zona de interseção entre a saúde mental e o SAMU, criada na realidade dos serviços de saúde no Brasil a partir da consolidação das diretrizes da reforma psiquiátrica e da Política Nacional de Atenção às Urgências. Esta é uma área repleta de contradições, por agregar compreensões e conceitos de assistência que divergem em vários aspectos: de um lado a saúde mental, com todas as suas ideias de inclusão, respeito às singularidades, valorização do aspecto subjetivo, promoção de diálogo, intensificação das relações humanas como elemento terapêutico e luta pela construção de cidadania e justiça social para seus pacientes; e do outro o SAMU, setor de urgência onde imperam a objetividade, a otimização do tempo, a valorização de equipamentos sofisticados, a visão mecanicista e biológica do ser, a compreensão das ações pelo binômio causa-efeito e a extrema formalização técnica de suas ações, sempre desenvolvidas via construção de protocolos.

Nesse sentido, este artigo tem por objetivo discutir os princípios e diretrizes que norteiam a atenção de urgência prestada pelo SAMU durante uma crise ou urgência/emergência psiquiátrica, tendo como parâmetro as discussões que embasaram a reforma psiquiátrica.

\section{MÉTODO}

Trata-se de uma revisão não sistemática de literatura, construída como suporte teórico de uma dissertação de mestrado defendida junto ao Programa de Pós-Graduação em Enfermagem da Universidade Federal do Rio Grande do Norte.

A discussão tem como tema central a busca pela articulação entre os princípios e diretrizes da Política Nacional de Atenção às Urgências que norteiam o serviço do SAMU e reflexões sobre o movimento pela reforma psiquiátrica brasileira, ambas presentes na atual política de atenção à saúde mental no Brasil.

As referências utilizadas no texto foram selecionadas nas bases de dados da Biblioteca Virtual em Saúde e por meio de busca manual realizada em bibliotecas e em periódicos disponibilizados na internet. Além disso, também obras de autores clássicos na área da saúde mental e no contexto da reforma psiquiátrica foram lidas, fichadas e referenciadas.

Neste sentido, artigo compõe uma revisão crítica que não se ocupa somente em trazer um apanhado de ideias sobre a temática, mas buscou estabelecer um diálogo entre os autores referenciados, na perspectiva de fazer uma discussão sobre o serviço do SAMU no atendimento às crises e urgências/emergências psiquiátricas.

\section{RESULTADOS E DISCUSSÃO}

Em termos práticos, o atendimento no SAMU acontece da forma descrita a seguir. Quando o serviço é acionado através da rede 192, a chamada é atendida inicialmente pelo Técnico Auxiliar de Regulação Médica - TARM, que deve acalmar o solicitante, 
anotar a localização do incidente de forma precisa, colhendo dados detalhados, buscar o motivo da chamada e passar o caso para o médico regulador. Este, por sua vez, identifica a origem da chamada (via pública, domicílio, prédios comerciais, etc.), o perfil do solicitante (médico, profissionais de saúde não médicos, profissionais de áreas afins ou leigos); em seguida essas informações são confrontadas com a gravidade do caso e o médico regulador, com base nesses dados e na territorialização dos serviços de emergência disponíveis no momento, envia o recurso mais apropriado (Portaria 2048/GM, 2002).

Em geral, o médico regulador tem à sua disposição dois tipos de ambulância, conforme a gravidade do caso: a de suporte básico de vida e a de suporte avançado de vida. Nas ocorrências mais graves, o referido profissional envia uma viatura de suporte avançado de vida, que conta com um socorrista condutor, um enfermeiro e um médico para a realização de ações invasivas e de maior complexidade. Logicamente, esta ambulância está equipada com todos os instrumentos de uma UTI móvel. Nas ocasiões de menor gravidade, a regulação envia a viatura de suporte básico de vida, onde estão presentes um socorrista condutor e um técnico de enfermagem, além do aparato tecnológico básico para a realização de manobras de caráter não invasivo (Portaria 2048/GM, 2002).

Ao chegar à cena da ocorrência a equipe faz uma avaliação geral do local, observando a segurança, o número de vítimas e suas condições clínicas, e em seguida proceda à prestação dos cuidados necessários e ao encaminhamento para o tratamento definitivo. Depois da chegada ao local e durante todo o transporte é mantido contato com o médico regulador, que continuará a deliberar sobre as decisões mais apropriadas, tendo em vista os recursos disponíveis no momento.

Em geral, no socorro prestado pelo SAMU durante as ocorrências psiquiátricas são encaminhadas viaturas que contam apenas com equipamentos básicos e com a presença de um socorrista condutor e um técnico de enfermagem, conforme as diretrizes para regulação médica estabelecidas na Política Nacional de Atenção às Urgências. Esses profissionais têm a função de se deslocar até o local do evento, comunicar-se com o médico regulador e seguir suas orientações para estabelecer condutas.

No que se refere à construção de competências para essa atuação, A Portaria 2048/GM (2002) estabelece que o socorrista deverá receber um treinamento de quatro horas teóricas e nenhum treinamento prático, e o técnico de enfermagem, de duas horas teóricas e quatro práticas sobre as ocorrências psiquiátricas.

O serviço de atenção à saúde mental, principalmente durante as intervenções em crise, requer dos profissionais envolvidos conhecimento, competências, técnicas e habilidades singulares, porém a carga horária supracitada para a capacitação dos profissionais do SAMU na atuação em situações de crise e urgência/emergência psiquiátrica é ínfima diante dessas necessidades. Soma-se a isso o fato de que a formação - tanto dos cursos profissionalizantes de nível médio como dos cursos de nível superior na área de saúde - também destina pouca atenção à área de saúde mental em suas grades curriculares. Essas deficiências na formação inicial e complementar dos profissionais de saúde podem ter implicações na qualidade da atenção prestada durante as crises psíquicas.

O impacto desse problema poderia ser minimizado em médio prazo caso o apoio matricial previsto nas diretrizes para a atenção à saúde fosse operacionalizado. Trata-se de uma estratégia ministerial para integrar a atenção à saúde mental aos serviços de saúde em geral sem prejuízos assistenciais decorrentes do despreparo profissional. Para tanto, é prevista a formação de uma equipe matricial de referência em saúde mental, composta por profissionais especializados na área, com a responsabilidade de apoiar os serviços na melhoria da assistência ao sujeito em sofrimento psíquico, porém isso ainda acontece de forma muito incipiente. Além disso, é também frágil o Programa Permanente de Formação de Recursos Humanos para a reforma psiquiátrica, que incentiva a formação de núcleos para capacitação em saúde mental (Ministério da Saúde, 2007).

Pode-se perceber que os serviços de urgência ocupam um lugar tão estratégico quão problemático na rede de saúde mental, pois estão no último nível antes da internação psiquiátrica. Isso coloca o serviço em uma posição privilegiada no tocante à percepção de problemas, ao desenvolvimento de estratégias mais resolutivas e a tomadas de decisões pertinentes durante o fluxograma do usuário nos diversos níveis da rede, servindo como instrumento para evitar internações desnecessárias (Campos \& Teixeira, 2001). Por outro lado, pela discussão se percebe que esses serviços previstos na Lei 10.216/01 são muito pouco explorados no meio acadêmico e científico, o que frequentemente leva ao surgimento de conflitos (Jardim \& Dimenstein, 2007).

Em estudo realizado no SAMU de Aracaju, Jardim (2008) evidenciou que, em alguns casos, o 
serviço se recusa a atender ocorrências psiquiátricas, e, quando o faz, utiliza a imobilização física como o seu principal trunfo. Dessa maneira, a autora ressalta que o SAMU atua na realidade de saúde mental como um controlador de corpos e mantenedor da ordem social.

É importante destacar que o fato de o médico regulador enviar as ambulâncias de suporte básico de vida, em conformidade com os critérios de regulação para as urgências psiquiátricas contidos na Portaria 2048/GM (2002), tem em muito contribui para a ocorrência de abusos durante a realização da contenção física ou na tomada de medidas repressivas e violentas por parte da equipe do SAMU, diante da agitação e/ou agressividade eventualmente verificadas em uma situação de crise. Acontece que esse tipo de viatura não dispõe de nenhum fármaco com atividade psicoativa ou com capacidade de promover sedação em situações de urgência ou emergência onde ela se faça necessária. Nessa situação, um profissional despreparado pode tomar medidas inapropriadas, com base na emoção da situação, no seu próprio medo e nos seus preconceitos relacionados ao sujeito em sofrimento psíquico.

Destarte, a impossibilidade do uso do psicotrópico nas ambulâncias de suporte básico de vida, que são responsáveis pela maioria dos atendimentos psiquiátricos na realidade do SAMU, traz prejuízos significativos à assistência prestada. Basaglia (2005) contribui para essa questão quando afirma: "se o doente perdeu sua liberdade por causa da doença, a liberdade de tomar a posse de si mesmo lhe foi dada pelo fármaco (...)" (p. 27).

Em contrapartida, nos casos em que a ambulância de suporte avançado de vida, dotada de medicamentos psicotrópicos, é enviada pelo médico regulador para a ocorrência de crise ou urgência/emergência psiquiátrica, a presença de profissionais com pouca qualificação e preparo na área de saúde mental pode levar ao abuso na utilização das drogas psicotrópicas, o que pode levar a impregnação tóxica e a prejuízos irreparáveis à saúde mental e clínica dos sujeitos. Não estamos defendendo aqui o fármaco como a única resposta a uma situação de intensificação do sofrimento psíquico, mas também não negamos a importância da psicofarmacologia no atendimento de urgência em saúde mental (Venturini, 2003).

Neste sentido, o emprego da psicofarmacologia deve ser apenas mais um componente envolvido da complexa rede para intervenção nas urgências em saúde mental. Ao utilizar o fármaco temos que levar em consideração a totalidade do usuário em seu contexto e em sua subjetividade (Saraceno, Asioli \&
Tognoni, 1994). Desta forma, não estamos negando todo o legado de contribuições da farmacologia para a saúde mental, estamos apenas criticando uma postura reducionista nas suas práticas, que não podem tomar um sentimento humano como um simples emaranhado de reações químicas entre neurotransmissores.

$\mathrm{O}$ uso indiscriminado de medicamentos psicotrópicos visa, na maioria das vezes, à sedação e à contenção rápida dos "incômodos" causados pela crise, sem que haja o respeito pelo tempo que o sujeito precisa para manifestar seu sofrimento. Não é fácil, para uma sociedade que não estava habituada a conviver de forma intensa com as manifestação da loucura no seu cotidiano, deparar-se com a crise e com todo o seu estigma construído social e historicamente. Partindo desse pressuposto, tudo que foge ao normal precisa ser restabelecido com prontidão. Assim os serviços de emergência apresentam-se para as necessidades sociais como medidas e estratégias que precisam ser acionadas para equalizar o sujeito e enquadrá-lo nas normas. Para tanto, torna-se justificável aos olhos de profissionais de emergência e para a sociedade o uso de contenção mecânica, confinamento, sedação inapropriada e toda forma de violência simbólica e física (Jardim, 2008).

Prova disso é que, segundo Amarante (2000), para a sociedade, "as instituições psiquiátricas, como as demais instituições, funcionam bem, na medida em que são capazes de dar respostas rápidas, funcionais e objetivas aos problemas que se lhe apresentam" (p. 96).

Percebe-se que a herança do modelo de intervenção em crise, criado por Caplan na sua lógica de preventivista, somada todo o preconceito e estigma historicamente construídos em torno do paciente psiquiátrico, mostra para a sociedade a loucura como algo a ser corrigido. Nessa lógica, toda a sua sintomatologia deve ser rapidamente extirpada e veementemente combatida.

Outro fator que contribui para essa prática é que os aspectos normativos da Política Nacional de Atenção às Urgências tratam as ocorrências psiquiátricas com as mesmas diretrizes com as quais são operacionalizadas as urgências traumáticas, clínicas e obstétricas, ou seja, durante a assistência imperam o fator tempo, a ação protocolar e uniformizada e o encaminhamento para internação. Com base nisso, o que o SAMU faz normalmente nas crises e urgências/emergências psiquiátricas é conter seus efeitos rapidamente e encaminhar o paciente para o hospital psiquiátrico; ou seja, onde a emergência poderia surgir ela é abruptamente amordaçada, são 
emudecidos os seus gritos e aprisionados os seus gestos desesperados.

A banalização desse tipo de assistência em um contexto em que os manicômios e suas práticas não são mais aceitos é uma grande contradição. Aliás, geralmente os serviços substitutivos surgidos em resposta ao fechamento dos manicômios no Brasil estão impregnados das práticas manicomiais (Dalmolim, 2006). Dessa forma, as intervenções repressivas e violentas durante as crises dão vida ao manicômio - não na sua figura institucional, com muros, setores e funcionários, mas sim, em uma forma simbólica, representada pela forma de agir violentamente na tentativa de restabelecer a ordem. Neste sentido, Amarante (2000) acrescenta: "A instituição psiquiátrica não é entendida tão somente como o manicômio, mas no conjunto de saberes e práticas operadas sob o título de psiquiatria clássica" (p. 87).

O uso de tais técnicas e práticas manicomiais durante as intervenções em crise favorece a apreensão da subjetividade e a criação de dependência institucional ou profissional por parte dos sujeitos em sofrimento psíquico, ao passo que medidas destinadas à reestruturação subjetiva do indivíduo, que respeitem sua singularidade, e não a necessidade de normatização, seriam capazes de fomentar autonomia e transformações significativas em suas vidas.

Agir violentamente durante a crise demonstra que o medo da loucura é o que está ditando o norte da assistência prestada. É importante destacar que o doente mental não é perigoso. Em situações de crise ele pode agir de forma inesperada, agressiva ou perigosa, como qualquer indivíduo em uma situação crítica, por isso a assistência nesses casos precisa contar com cuidados especiais prestados por profissionais com treinamento e conhecimento adequados (Campos \& Teixeira, 2001).

Essa discussão é importante para que os profissionais de saúde do SAMU, que lidam com essas situações extremas, não transfiram sua responsabilidade ao Corpo de Bombeiros ou à Polícia durante as ocorrências psiquiátricas, sem qualquer critério e com base somente no medo e em uma má interpretação da Portaria 2048/GM, que aponta para a possibilidade de intervenção dessas corporações. Caso contrário, segundo Goffman (1974), “a equipe psiquiátrica compartilha com a polícia a peculiar tarefa profissional de atemorizar e moralizar adultos" (p. 297).

O exercício dos saberes e práticas manicomiais durante a abordagem nas crises psiquiátricas por parte do SAMU pode encontrar respaldo no fato de que muitos profissionais de saúde inseridos nos serviços de urgência que atendem demandas psiquiátricas são egressos de instituições fechadas que deixaram de funcionar após a reforma psiquiátrica (Jardim \& Dimenstein, 2007).

Por outro lado, a maneira violenta de abordar um sujeito em crise pode também ser reflexo de uma compreensão errônea dos profissionais do SAMU sobre as diretrizes que orientam a Política Nacional de Atenção às Urgências, segundo as quais toda crise ou intensificação do sofrimento psíquico é uma urgência ou emergência psiquiátrica. Neste sentido, é necessário levar em consideração que nem toda crise é uma urgência ou emergência e que as intervenções devem pautar-se nessa classificação para que não aconteçam omissões ou exageros (Saraceno et al., 1994).

Não obstante, a sociedade, os familiares e muitos profissionais de saúde veem a crise, na maioria dos casos, como uma demanda urgente quando começa a afetar a rotina social. Na maior parte das ocorrências, as pessoas que se sentem incomodadas pelos comportamentos do sujeito em sofrimento psíquico decidem quando é necessário chamar os profissionais de emergência. Assim, naprática, o limiar entre crise e urgência psiquiátrica é estabelecido por leigos, que o fazem não com um olhar clínico, mas a partir de sua capacidade de suportar as manifestações e perturbações decorrentes do sofrimento do outro (Goffman, 1974).

Aliás, a definição do que sejam urgência, emergência e as prioridades para o atendimento é um aspecto bastante preocupante para toda a realidade de atendimento de emergência em saúde mental, e não somente para os leigos ou população em geral. Mesmo para os profissionais de saúde atuantes na área, a emergência e a urgência psiquiátrica são algo difícil de definir, uma vez que um quadro de agitação delirante pode ser tão grave quanto um de extrema passividade e lentidão de ações e pensamentos (Oliveira, 2002).

Nesse contexto, a clareza de que existem diferenças significativas entre a urgência médicopsiquiátrica é o primeiro ponto para compreender melhor o conceito desta em relação àquela. Ambas as situações envolvem riscos extremos, porém nas urgências psiquiátricas os indivíduos estão sujeitos a complicações em razão do seu estado emocional ou psíquico. Tais perturbações podem levá-los a cometer ações suicidas, de automutilação ou de atentado contra a sua integridade ou a vida alheia, o que transforma a urgência em uma emergência psiquiátrica. Esses são os reais limites da urgência e da emergência em saúde 
mental, os quais devem ser cuidadosamente avaliados antes e durante a abordagem dos profissionais de saúde (Oliveira, 2002).

Diante disso, nem toda situação de crise irá caracterizar, necessariamente, uma realidade de urgência ou emergência de saúde mental. Tratar toda crise como uma urgência ou emergência é o reflexo maior de nossa intolerância e preconceito contra os sujeitos em sofrimento psíquico; e acima de tudo, é uma demonstração de nossa incapacidade de compreender e de aceitar o outro, plantada em nosso cotidiano pela psiquiatria clássica. Não obstante, a crise em si, suas manifestações, a perturbação da ordem e o medo estigmatizado, que podem estar presentes na sociedade e nos profissionais durante esse acontecimento, não devem servir como justificativa para deixar a condição humana do sujeito em sofrimento em segundo plano durante o enfrentamento de uma crise.

Infelizmente, na realidade dos serviços de urgência, como é o caso do SAMU, o espaço dado para as manifestações de uma situação de crise de um sujeito é marcado por um processo em que profissionais e instituições negam completamente a probabilidade de escuta, interação ou diálogo com o paciente, afastando a possibilidade de acolhimento e tratamento adequados (Dalmolim, 2006).

Isso é potencialmente preocupante, pois o diálogo é um instrumento crucial para a apreensão de alguns elementos clínicos que podem nortear as condutas terapêuticas a serem tomadas. Por outro lado, escutar o sujeito não significa exclusivamente buscar sinais e sintomas para a construção de hipóteses diagnósticas ou simplesmente servir como instrumento de persuasão junto ao paciente (Campos \& Teixeira, 2001). A mola propulsora da ação de escuta e do diálogo deve ser a criação de vínculo, corresponsabilização e respeito mútuo, afinal o profissional de saúde não deve buscar a intensificação da relação profissional-doença, mas sim, a consolidação da interação terapêutica entre o profissional e o paciente, em uma relação de empatia (Oliveira, 2002).

No contexto de estabelecimento dessas relações, não se pode esquecer que o modo como os profissionais de saúde interagem com os instrumentos tecnológicos, com as dinâmicas institucionais e, principalmente, nas relações com os usuários e entre si, faz parte de um contexto construído e materializado no espaço coletivo; no entanto, nessa dinâmica também estão inseridos os interesses pessoais e morais, o medo e o preconceito de cada um. Isso também pode dificultar a criação de vínculos interpessoais com os usuários e seus casos, portanto devem e precisam ser mais bem trabalhados com os profissionais do SAMU (Bonfada, Cavalcanti, Araújo \& Guimarães, 2010).

A falta de articulação com a rede de saúde mental, a incapacidade e a rejeição dos hospitais gerais em receber o paciente psiquiátrico, o número reduzido de CAPSs III com funcionamento 24 horas e sete dias por semana na maioria das cidades brasileiras e o desconhecimento sobre as possibilidades terapêuticas dos serviços substitutivos da rede assistencial de saúde mental são fatores que contribuem para que o SAMU priorize o encaminhamento do paciente em crise para os prontos-socorros dos hospitais psiquiátricos, onde, na maioria das vezes, o paciente é direcionado à internação.

Contudo, quando o SAMU conduz um paciente diretamente para a internação em hospital psiquiátrico sem qualquer critério está desrespeitando a Portaria 224 de 29 de Janeiro de 1992, que prega o direcionamento dos pacientes em crise psiquiátrica para socorro nos hospitais gerais que, por sua vez, tem o dever de tomar medidas terapêuticas com o intuito de sanar as manifestações mais graves da crise e, em seguida, referenciar o paciente para um serviço de acompanhamento comunitário (Ministério da Saúde, 2004).

Negligencia, ainda, a proposta contida na Política Nacional de Saúde Mental que trabalha com o conceito de leitos de atenção integral em Saúde Mental, onde as instituições de saúde em geral em articulação com a rede de saúde mental, têm a obrigação de conjuntamente ofertar o acolhimento integral ao paciente em crise, utilizando-se dos serviços disponíveis em toda a rede, através dos mecanismos de referência e contra-referência. Esse processo é capaz de interromper a linha que inevitavelmente conduz o sujeito à internação psiquiátrica (Ministério da Saúde, 2007).

O fluxograma da internação é alimentado pelo próprio hospital psiquiátrico. Sua existência na rede gera a demanda assistencial, porquanto o SAMU e a sociedade percebem sua existência como necessária e esta última utiliza seus serviços quando o julga conveniente. Sendo assim, a atenção à crise em qualquer nível torna-se automaticamente resolvida com o encaminhamento do portador de transtorno mental para o isolamento.

Diante do exposto, uma apreciação precipitada poderia perceber a existência do SAMU como instrumento de intervenção na crise, o que já demonstraria uma realidade manicomial, uma vez que este serviço serve como mediador na promoção da 
internação pós-crise. Então é de perguntar se o SAMU deveria ser isento da responsabilidade com as urgências psiquiátricas. A resposta seria que, se o serviço se voltasse para um modelo de atenção à crise na comunidade, em articulação com toda a rede assistencial em saúde mental, ele seria absolutamente importante, não se limitando a ser um mero veículo ou canal para conduzir à internação.

É preciso que os serviços de urgência e emergência, tanto no seu componente móvel quanto no fixo, percebam o momento da crise como fundamental para propiciar acolhimento e compreensão da subjetividade manifesta na intensificação do sofrimento do usuário (Dalmolim, 2006).

É de uma incoerência extrema toda a rede de assistência em saúde mental se estruturar na perspectiva de rompimento com os moldes da psiquiatria dominante $\mathrm{e}$ a atenção às crises priorizar $\mathrm{e}$ reforçar esses moldes. É preciso recusar os conceitos arcaicos e buscar interação com o sujeito em sofrimento. Precisamos voltar nossos olhares às pessoas, e não às suas doenças. Dessa forma, podemos construir espaços terapêuticos onde seja possível escutar e acolher angústias e experiências vividas, mesmo em situações de crise (Amarante, 2007). Afinal, a crise não pode ser apreendida por um viés que a limite a um conjunto de manifestações específicas; ela significa, antes de tudo, a vivência de um momento difícil na vida de uma pessoa ou grupo, mas, mesmo em momentos tão complexos, não é justificável que se alterem as técnicas de intervenção terapêutica em prol da efetivação da repressão e violência.

É necessária uma clínica capaz de pôr em foco tanto o sujeito do sofrimento como o profissional que o acolhe. Logicamente, quando falamos em clínica não estamos nos referindo à tradicional, pautada na visão patológica e no saber médico especializado. Referimo-nos a uma clínica que construa possibilidades e subjetividade e que possa afetivamente se tornar responsável diante dos problemas humanos, especialmente pelo cuidado integral aos sujeitos em sofrimento psíquico (Amarante, 2003).

Tomamos como exemplo o uso de psicotrópicos durante as intervenções em crise. Rotineiramente, a clínica tradicional aponta o medicamento como estratégia para debelar os sintomas psiquiátricos, acabando rapidamente com a crise e com suas manifestações mais desagradáveis. Dessa forma, a psicofarmacologia é usada como estratégia de manutenção da ordem, processo em que o paciente e sua terapêutica são elementos secundários. Por outro lado, pode ser de alta conveniência uma aplicação responsável de fármacos em saúde mental, que tenha como elemento central o projeto terapêutico singular do usuário, de forma que as drogas auxiliem no estabelecimento de vínculo com a realidade para a construção de relações no tratamento do paciente (Ferigato et al., 2007).

Destarte, o foco dessa discussão não está na negação da importância da clínica, muito pelo contrário, esta é um instrumento valioso e imprescindível em eventos inevitáveis, por dispor de terapêuticas e ações vitais em situações críticas. $\mathrm{Na}$ verdade, o que está se ressaltando é a discussão sobre os limites e as possibilidades de um modelo de atenção construído historicamente como desarticulado, curativista, biologicista e pautado nos binômios de causa/efeito e queixa/conduta. Dito de outra forma, trata-se do reconhecimento da insuficiência desse modelo e da necessidade de transformação (Bonfada, Cavalcanti, Araújo, \& Guimarães, 2012).

A transformação da clínica e da forma de perceber as crises psíquicas e nelas atuar, em especial no espaço de atenção do SAMU, é de fundamental importância para a consolidação da reforma psiquiátrica; porém essa transformação não irá acontecer do dia para noite, visto que sua construção tem fortes raízes históricas atreladas ao modelo preventivista americano e ao da psiquiatria clássica para intervenção em crise.

A mudança desse cenário requer uma transformação dos saberes e da formação dos profissionais de saúde, pois, pelo conhecimento a prática pode ressignificar suas intervenções; mas a transformação do espaço acadêmico também enfrenta seus entraves no contexto atual. As instituições de ensino, especialmente as privadas, que já constituem a maioria no Brasil, claramente se tornaram empresas, onde o aluno é o consumidor e o professor é o vendedor do ensino de acordo com o gosto do freguês. Nesse contexto, a formação não permite a construção da crítica e perpetua o dogmatismo preconceituoso (Patto, 1999).

Além disso, a clínica tradicional tem pautado a formação em saúde na maioria das instituições de ensino superior no Brasil. Nesses lócus, os profissionais são formados a partir do biologicismo, mecanização e tecnificação do saber e do agir em saúde, o que os torna incapazes de atuar a partir da e para a dimensão subjetiva dos indivíduos ou coletividade, condição indispensável durante a abordagem de crise. 
$\mathrm{Na}$ dimensão particular dos serviços de atendimento as crises, urgências e emergências psiquiátricas - como é o caso do SAMU, que lida com sofrimento psíquico em alta complexidade -, a criação de espaços de interlocução, para que os profissionais da equipe possam ter uma oportunidade de comunicação, discussão, troca de experiência, aprendizado e cuidados mútuos é fundamental para o fortalecimento coletivo e a construção de competências necessárias para o atendimento em crise. Tais momentos podem contribuir também para a desconstrução de angústias, preconceitos, medos e culpa presentes nos profissionais, elementos que, de forma isolada ou associadamente, podem ser determinantes do modo como a assistência é prestada (Ferigato et al., 2007).

Desconstruir a urgência em restabelecer o equilíbrio perdido e avançar na compreensão de que o sujeito e o seu sofrimento psíquico assumem a centralidade durante as intervenções em crise são fatores que propiciam a reorganização das relações do paciente com o mundo que o cerca e com ele mesmo, por isso deve ser esta a prioridade dos serviços de urgência psiquiátrica (Oliveira, 2002).

Não se pode deixar de ressaltar a necessidade de se proceder a uma revisão dos códigos civil e penal, bem como de outras leis e decretos que inclusive compõem as políticas públicas de saúde e estão recheados de dizeres preconceituosos sobre portadores de transtornos mentais. Isso é um elemento que dificulta o exercício da cidadania (Amarante, 2007). Por outro lado, a cidadania e seu exercício não se conseguem por decreto ou por força da lei, ela é somente mais um elemento desse processo. A sua construção se dá em um contexto social complexo, que engloba o universo da prática, atitudes e relações humanas.

\section{CONSIDERAÇÕES FINAIS}

Diante do pressuposto de que todo cidadão brasileiro deve ter acesso aos serviços públicos de saúde, qualquer que seja sua necessidade, podemos afirmar que a inserção de ações de saúde mental na rede de saúde em geral significa um avanço na construção da cidadania para os sujeitos em sofrimento psíquico; porém essa transferência de responsabilidade não pode acontecer de forma aleatória, ou seja, sem um processo de preparação dos profissionais, que não estão habituados a lidar com uma condição tão particular quanto a do sofrimento psíquico. Deficiências na formação inicial e/ou continuada em saúde mental podem tornar-se elemento propulsor de ações violentas, de cunho repressivo e sem fins terapêuticos, tais como solicitar desnecessariamente força policial e fazer mau uso da contenção física ou química.

Em síntese, a grande necessidade apresentada ao longo da discussão é que a crise seja compreendida como uma manifestação que é individual, mas se apresenta e se desenvolve no âmbito coletivo, com todas as incoerências e antagonismos decorrentes da sua construção social e histórica. Também é necessário que a assistência prestada nesses casos procure manter os laços sociais, ambientais e afetivos dos sujeitos, evitando medidas violentas, de cunho repressor ou excludente, que possam comprometer a criação de novas e futuras relações por parte dos pacientes em crise.

Por outro lado, é perceptível que a carga horária para a capacitação dos profissionais que vão lidar diretamente com os sujeitos no momento de maior intensificação do seu sofrimento psíquico é mínima, ainda mais em se tratando de profissionais de nível médio. Esses profissionais, pelo perfil técnico do curso, não dispõem de aprofundamento especial em saúde mental, área que, historicamente, sofre a influência do estigma social, o qual pode ser identificado pela desvalorização da formação, evidenciada por sua reduzida carga horária.

Além disso, a Portaria 2048/GM, que estabelece as diretrizes para o funcionamento do SAMU, não prevê o teor dos conteúdos trabalhados junto aos profissionais, apenas descreve rapidamente o que se espera de cada um deles durante o exercício profissional. Esse contexto abre espaço para que o saber da psiquiatria positivista, que impera nas academias médicas e tem reflexos nos demais campos da saúde, perpetue-se e perpetue as práticas de contenção física ou química e vê o simples transporte para o internamento como a única possibilidade de ação nas intervenções em crises e nas urgências psiquiátricas.

Os desafios são imensos e os questionamentos são complexos, mas ao mesmo tempo esses elementos são mais um estímulo para a produção de conhecimentos científicos que venham a contribuir para a consolidação de uma intervenção em crise pelo SAMU mais humanizada e articulada com a reforma psiquiátrica brasileira, garantindo cidadania e inserção social aos sujeitos em sofrimento psíquico. Caso contrário, como aponta Goffman (1974), "os doentes mentais podem ser esmagados pelo peso de um ideal de serviço que torna a vida mais fácil para todos nós" (p.312). 


\section{REFERÊNCIAS}

Amarante, P. (1999). Manicômios e loucura no final do século e do milênio. In M. I. A. Fernandes, I. R. Scarcelli, \& E. S. Costa (Orgs.), Fim de século: ainda manicômios? (pp. 47-53). São Paulo: IPUST.

Amarante, P. (2000). O homem e a Serpente: outras histórias para a loucura e a psiquiatria. Rio de Janeiro: Fiocruz.

Amarante, P. (2003). A Clínica e a Reforma Psiquiátrica. In P. Amarante (Org.), Arquivos de Saúde Mental $e$ Atenção Psicossocial (pp. 45-66). Rio de Janeiro: Nau.

Amarante, P. (2007). Saúde Mental e Atenção psicossocial. Rio de Janeiro: Fiocruz.

Basaglia, F. (2005). Escritos selecionados em saúde mental e reforma psiquiátrica. Rio de Janeiro: Garamond.

Bonfada, D., Cavalcanti, J. R. L. P., Araújo, D. P., \& Guimarães, J. (2010). A organização tecnológica na produção de serviços de saúde: (Re)Conhecendo Limites, Abraçando Perspectivas. Revista de Enfermermagem da UFPE On Line, 4(1), 1-7.

Bonfada, D., Cavalcanti, J. R. L. P., Araújo, D. P., \& Guimarães, J. (2012). A integralidade da atenção à saúde como eixo da organização tecnológica nos serviços. Ciência \& Saúde Coletiva, 17(2), 555-560.

Campos, C. J. G., \& Teixeira, M. B. (2001). O atendimento do doente mental em pronto-socorro geral: sentimentos e ações dos membros da equipe de enfermagem. Revista da Escola de Enfermagem da USP, 35(2), 141-149.

Dalmolim, B. M. (2006). Esperança equilibrista: cartografias de sujeitos em sofrimento psíquico. Rio de Janeiro: Fiocruz.

Ferigato, S. H., Campos, R. T. O., \& Ballarin, M. L. G. S. (2007). O atendimento à crise em saúde mental: ampliando conceitos. Revista de Psicologia da UNESP, 6(1), 31-44.

Goffman, E. (1974). Manicômios, Prisões e Conventos. São Paulo: Perspectiva.

Jardim, K. F. S. B. (2008). O Serviço de Atendimento Móvel de Urgência (SAMU) no contexto da reforma psiquiátrica: em análise a experiência de Aracaju/SE. Dissertação de mestrado Não-Publicada, Centro de
Ciências Humanas, Letras e Artes, Universidade Federal do Rio Grande do Norte, Natal.

Jardim, K. F. S. B., \& Dimenstein, M. (2007). Risco e crise: pensando os pilares da urgência psiquiátrica. Psicologia em Revista, 13(1), 169-189.

Lei no. 10.216 (2011, 6 de abril). Dispõe sobre a proteção e os direitos das pessoas portadoras de transtornos mentais e redireciona o modelo assistencial em saúde mental. Brasília, DF.

Ministério da Saúde. (2004). Legislação em saúde mental: 1990 a 2004 (5a ed.). Brasília, DF: Autor.

Ministério da Saúde. (2007). Saúde mental no SUS: acesso ao tratamento e mudança no modelo de atenção, relatório de gestão 2003-2006. Brasília, DF: Autor.

Oliveira, P. R. M. (2002). Valorizando a palavra na emergência psiquiátrica: a recepção das diferenças. Dissertação mestrado Não-Publicada, Escola Nacional de Saúde Pública, Fundação Oswaldo Cruz, Rio de Janeiro.

Patto, M. H. S. (1999). Formação profissional, compromisso político e luta antimanicomial. In Fernandes, M. I. A., Scarcelli, I. R., \& Costa, E. S. (Orgs.), Fim de século: ainda manicômios? (pp. 109122). São Paulo: IPUST.

Portaria 2048/GM. (2002, 5 de novembro). Dispõe sobre o funcionamento dos Serviços de Urgência e Emergência. Brasília, DF: Ministério da Saúde.

Saraceno, B., Asioli, F., \& Tognoni, G. (1994). Manual de saúde mental. São Paulo: Hucitec.

Venturini, E. (2003). A qualidade do gesto louco na época da apropriação e da globalização. In P. Amarante (Org.), Arquivos de Saúde Mental e Atenção Psicossocial (pp. 157-184). Rio de Janeiro: Nau.

Recebido em 21/05/2010 Aceito em 28/07/2012
Endereço para correspondência:

Diego Bonfada. Rua José Mauro de Vasconcelos, 1778, apto 401, Bairro Capim Macio, CEP 59082-210, Natal-RN, Brasil. E-mail: diegobonfada@ hotmail.com. 